See Article page XXX.

\section{Commentary: Another glimpse of light for patients with Marfan syndrome}

\author{
Alan Gallingani, MD, Francesco Maestri, MD, \\ Francesco Nicolini, MD, PhD, and \\ Francesco Formica, MD
}

Marfan disease is the best-known congenital condition predisposing to the development of aortic disease. In recent years, there have been many publications addressing the surgical management of type A aortic dissection in this population. ${ }^{1,2}$ The most common presentation of patients with Marfan syndrome and aortic disease is root aneurysm involving the ascending aorta; therefore, in the setting of type A acute aortic dissection, complete aortic root replacement is thought to be the most appropriate surgical approach. ${ }^{3}$ In contrast, despite the high rate of disease progression involving the aortic arch and descending aorta in patients with Marfan syndrome, there is no unanimous evidence that aggressive surgical treatment of the aortic arch should be performed in acute presentations when the entry tear is not located in the arch., ${ }^{4,5}$

The study by Farag and colleagues ${ }^{6}$ presents data on a relatively large population with Marfan syndrome; moreover, the cohort of patients examined was taken from the German Registry for Acute Aortic Dissection Type A (GERAADA), which includes centers in several European countries. This heterogeneity of participating centers provides an excellent basis for robust data analysis. In addition, the article by Farag and colleagues ${ }^{6}$ is based on patients who underwent surgery from 2006 to 2015, a relatively recent period compared with other high-profile

\footnotetext{
From the Cardiac Surgery Unit, University Hospital of Parma, and Department of Medicine and Surgery, University of Parma, Parma, Italy.

Disclosures: The authors reported no conflicts of interest.

The Journal policy requires editors and reviewers to disclose conflicts of interest and to decline handling or reviewing manuscripts for which they may have a conflict of interest. The editors and reviewers of this article have no conflicts of interest.

Received for publication July 31, 2021; revisions received July 31, 2021; accepted for publication Aug 3, 2021.

Address for reprints: Francesco Formica, MD, UO Cardiochirurgia, Azienda Ospedaliera Universitaria di Parma, Via Antonio Gramsci, 14, 43126 Parma, Italy (E-mail: francescoformica.hs@gmail.com).

J Thorac Cardiovasc Surg 2021; $\mathbf{\square}: 1-2$

$0022-5223 / \$ 36.00$

Copyright (C) 2021 by The American Association for Thoracic Surgery

https://doi.org/10.1016/j.jtcvs.2021.08.011
}

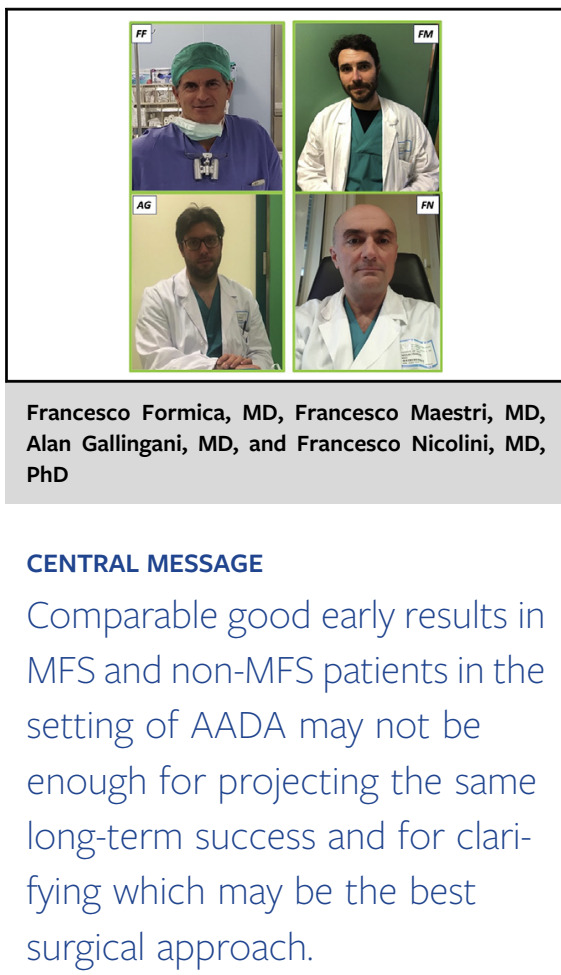

articles regarding type A aortic dissection in the Marfan population.

One aspect of the study by Farag and colleagues ${ }^{6}$ that could be considered its Achilles heel is the lack of a standardized definition of arch surgery and all of its variants. It is recognized that replacement of the ascending aorta with an open distal anastomosis compared with total arch replacement (frozen elephant trunk, elephant trunk, or any type of debranching technique) does not result in similar outcomes. In addition, analysis of early mortality without accurately defining the surgical procedure does not provide prospective validity to the study.

In most cases, type A aortic dissection presents as a surgical emergency, and therefore a definitive preoperative diagnosis of Marfan syndrome is often not feasible. As reported in the article, aortic root replacement is emerging as the gold standard technique in patients with Marfan syndrome, whereas analysis of the study population shows that only $30 \%$ of the Marfan sample in both the matched and unmatched groups underwent this operation. Perhaps this could be explained by the low rate of preoperative diagnosis of Marfan syndrome?

Finally, we congratulate the authors for their contribution to clarify the acute management of this shape-shifting disorder in this unique subset of individuals. In light of the excellent early results in the emergency setting of type A 
aortic dissection in patients with Marfan syndrome, more extensive mid- and long-term follow-up would be advisable because of the high rate and broad spectrum of aortic disease progression in this population. In addition, long-term results will demonstrate which surgical technique is the most appropriate and should therefore be standardized. Any valuable scientific contribution, such as that of Farag and colleagues, is important to provide further glimpses of light for patients affected by Marfan syndrome.

\section{References}

1. de Beaufort HWL, Trimarchi S, Korach A, Di Eusanio M, Gilon D, Montgomery DG, et al. Aortic dissection in patients with Marfan syndrome based on the IRAD data. Ann Cardiothorac Surg. 2017;6:633-41.
2. Rylski B, Bavaria JE, Beyersdorf F, Branchetti E, Desai ND, Milewski RK, et al. Type A aortic dissection in Marfan syndrome: extent of initial surgery determines long-term outcome. Circulation. 2014;129:1381-6.

3. Kimura N, Aizawa K, Kawahito K, Itagaki R, Yamaguchi A, Misawa Y, et al. Outcomes of early-onset acute type A aortic dissection-influence of etiologic factors. Circ J. 2019;83:285-94.

4. Schoenhoff FS, Carrel TP. Re-interventions on the thoracic and thoracoabdominal aorta in patients with Marfan syndrome. Ann Cardiothorac Surg. 2017;6: 662-71.

5. Ma WG, Zhang W, Zhu JM, Ziganshin BA, Zhi AH, Zheng J, et al. Longterm outcomes of frozen elephant trunk for type A aortic dissection in patients with Marfan syndrome. J Thorac Cardiovasc Surg. 2017;154: 1175-89.

6. Farag M, Büsch C, Rylski B, Pöling J, Dohle DS, Sarvanakis K, et al. Early outcomes of patients with Marfan syndrome and acute aortic type A dissection. J Thorac Cardiovasc Surg. July 21, 2021 [Epub ahead of print]. 